\title{
Morphology, Topography and Clinical Significance of Primary Nutrient Foramina in Tibia
}

\author{
Suja R.S. ${ }^{1}$, Mini Alikunju², Aswathy Maria Oommen³ ${ }^{3}$ Sreekumar R ${ }^{4}$, Sheena Kalyani Sukumaran ${ }^{5}$, \\ Chandra Mohan Nair Kaleeluvilayil Ragbavannair ${ }^{6}$, Lincy Varghese ${ }^{7}$, Swapna Thampi ${ }^{8}$ \\ 1, 2, 3, 4, 5, 6, 7, 8 Department of Anatomy, Government Medical College, Trivandrum, Kerala, India.
}

\section{ABSTRACT}

\section{BACKGROUND}

Nutrient foramina are seen in the shaft of long bones. They vary in number, size and their position on the surface of bones. It transmits the nutrient artery which is the main source of blood supply to the long bones. We intend to study the location, number, type and direction of primary nutrient foramina (PNF) on the shaft of tibia.

\section{METHODS}

The descriptive study was done using 120 tibiae (right-66, left-54) from Department of Anatomy, Govt. Medical College, Thiruvananthapuram. Length of each bone and distance of the nutrient foramen from the upper end of tibia was measured using osteometric board. The location of the primary nutrient foramina on the surface of tibia, the direction of the nutrient canal and the presence of secondary nutrient foramina were noted.

\section{RESULTS}

Single primary nutrient foramina were located on the posterior surface of 113 tibiae. 4 tibiae showed PNF and secondary nutrient foramina (SNF). No nutrient foramina were observed in 3 tibiae.

\section{CONCLUSIONS}

The precise knowledge and topography of PNF of tibia will help orthopaedic surgeons in minimising damage to vasculature of tibia during various surgical procedures.

\section{KEY WORDS}

Tibia, Nutrient Foramen, Nutrient Artery
Corresponding Author: Dr. Sreekumar $R$, Flat No. 615, Block No 4, EMS Nagar, Pattor,

Vanchiyoor P.O - 695035,

Trivandrum, Kerala, India.

E-mail:drsreekumarrs@gmail.com

DOI: $10.14260 / \mathrm{jemds} / 2021 / 214$

How to Cite This Article:

Suja RS, Alikunju M, Oommen AM, et al. Morphology, topography and clinical significance of primary nutrient foramina in Tibia. I Evolution Med Dent Sci 2021;10(14):999-1002, 10.14260/jemds/2021/214

Submission 07-11-2020,

Peer Review 04-02-2021,

Acceptance 11-02-2021,

Published 05-04-2021.

Copyright (C) 2021 Suja R.S. et al. This is an open access article distributed under Creative Commons Attribution License [Attribution 4.0 International (CC BY 4.0)] 


\section{BACKGROUND}

Skeleton of leg is formed by two long bones, tibia and fibula, the former lies medial to the later. The tibia is more massive and represent pre axial bone. Tibia participates in the formation of knee. Tibia presents upper end, lower end, and shaft. Skeleton of leg is formed by two long bones, tibia and fibula, the former lies medial to the later. The tibia is more massive and represent pre axial bone. Tibia participates in the formation of knee joint.

The upper end is expanded and bears prominent medial and lateral condyles which articulate with corresponding femoral condyles separated by fibro-cartilaginous menisci. The shaft of tibia is triangular on cross section and presents three borders, (anterior, medial and lateral) and three surfaces (medial lateral and posterior). Anterior border is entirely subcutaneous and extends from the tibial tuberosity and is continuous below with the anterior border of medial malleolus. The medial border is continuous below with the posterior margin of medial malleolus. Lateral border is sharp. Medial surface intervenes between anterior and medial borders. Lateral surface intervenes between anterior and interosseous borders. Posterior surface intervenes between medial and lateral borders and is sub divided by soleal line into an upper small triangular area and a lower large area.

Lower end of tibia is expanded and projects medially as the medial malleolus. The inferior surface of the lower end including medial malleolus is articular and receives the body of talus. Tibia is usually ossified from three centres, one primary centre for the shaft, two secondary centres-one for each end. The centre for the shaft appears at about seventh week of intrauterine life, near the middle of the shaft. The centre for the upper end appears either at birth or shortly after birth. The centre for the lower end starts between one and two years. The lower epiphysis fuses with the shaft at about fifteen to sixteen years, and the fusion of the upper epiphysis takes place between seventeen and eighteen years.

Vascular supply of tibia: the proximal end of tibia is supplied by metaphyseal vessels from the genicular arterial anastomosis. Nutrient foramen usually lies near the soleal line and transmits a branch of the posterior tibial artery. On entering the bone, it divides to give more ascending than descending branches. The periosteal supply to the shaft arises from the anterior tibial artery and from muscular branches. The distal metaphyses is supplied by branches from the anastomosis around the ankle. ${ }^{1}$

The main source of arterial supply to long bone is derived from the nutrient artery. Nutrient artery enters the long bone through nutrient foramen. ${ }^{1}$ Nutrient foramen is generally directed away from the growing end of the bone. ${ }^{2}$ In tibia, nutrient foramen is generally directed downwards because upper end is growing. Nutrient artery to tibia is a branch of posterior tibial artery. Sometimes it may arise from bifurcation of popliteal artery or anterior tibial artery. ${ }^{3}$ Arterial supply from nutrient artery is vital especially during early embryonic stages and periods of active growth.

Nutrient artery provides $70-80 \%$ of blood supply to the long bones in children and if the blood supply is decreased, it may lead to ischemia of bone resulting into less vascularisation of metaphysic and growth plate. ${ }^{4}$ It is very important for surgeons to have precise knowledge of nutrient foramina prior to surgery to ensure good success of surgical procedure and to improve prognosis. ${ }^{5}$ The tibia is commonly involved in several surgical procedures like bone grafting, the knee replacement, and external and internal fixation of fractures and bone resection of tumours. ${ }^{6}$ Therefore this study was conducted to understand topography of nutrient foramen on tibial shaft. Nutrient foramina are positioned on the flexor aspect of the long bones. ${ }^{7,8} \mathrm{~A}$ distinct groove leads to the primary nutrient foramen and the edges of the foramen are slightly raised. ${ }^{9}$ The study parameters will also be useful in anthropological and medico legal studies as the length of a bone can be calculated from the distance of the nutrient foramen from either end of the bone. This value then be used to reconstruct the height of an individual.

\section{METHODS}

This was a descriptive study conducted in the Department of Anatomy, Govt. Medical College, Thiruvananthapuram, Kerala, India from 2017 April to 2019 April, after receiving approval from the institutional research committee clearance with registration number IEC No. 06 / 23 / 2017 / MCT dated 17 / 04 / 2017. Sample selection was done according to the study of Chavda H.S and Jethva N K.17 For this study 120 dry adult tibiae available in the department were used. The age and sex were unknown. Fully ossified and complete bones were included in the study. Bones with pathological changes or any kind of deformity were excluded from the study. The right and left limb bones were measured. The total length of each tibia from the uppermost point on the superior surface of tibia to the lower end was measured using an osteometric board. The total length was divided into three segments, upper, middle and lower by marking a distance of 10,20 and $30 \mathrm{~cm}$ from the upper end of the bone. Primary nutrient foramina were identified by the presence of well-defined groove leading to it. Foramina that allowed the passage of a 24-gauge needle were considered as PNF and those with lesser diameter as secondary nutrient foramina (SNF). The number, direction and position on the surface of bone of the PNF were noted. The distance of the PNF from the upper end of tibia was also measured using osteometric board.

\section{Study Parameters}

a. TL: Total length of tibia from its upper end to the lower end in $\mathrm{cm}$.

b. PNF: Number of primary nutrient foramina.

c. D: Distance of the primary nutrient foramen from the upper end of tibia in $\mathrm{cm}$.

d. S1: Upper segment of tibia up to $10 \mathrm{~cm}$ from upper end.

e. S2: Middle segment of tibia up to $20 \mathrm{~cm}$ from upper end.

f. S3: Lower segment of tibia up to $30 \mathrm{~cm}$ from upper end.

g. SNF: Number of secondary nutrient foramina.

h. Direction of PNF.

\section{Statistical Analysis}

Parameters of the right and left sides were compared. Observations were tabulated in Microsoft Excel worksheet and average and standard deviation of total tibial length, average and standard deviation of the distance of nutrient foramina from proximal end of tibia were calculated. Percentage of PNF 
was calculated and the direction of PNF on the shaft of tibia was observed. $R$ software ( $R$ version-3.3 Aril 2016) was utilised for data analysis.

\section{RESULTS}

The mean total length of tibia on the right side was $35.57 \pm$ $2.48 \mathrm{~cm}$ and on the left side was $35.5 \pm 2.55 \mathrm{~cm}$. The mean distance of the PNF from the upper end of tibia on the right side was $11.73 \pm 1.72 \mathrm{~cm}$ and on the left side was $11.73 \pm 1.43$ cm (Table 1).

In the present study 117 (97.5\%) of tibiae showed presence of PNF. It was directed downwards and was located on the posterior surface of tibia. 59 of the 64 right tibiae had single PNF, 3 right tibia had 2 NF: one primary and one secondary, the secondary NF was directed upwards. 54 of the 56 left tibiae had single PNF, in one left tibia $2 \mathrm{NF}$ was observed: one primary and one secondary, the secondary NF was directed upwards. NF was not observed in two bones on right side $(1.6 \%)$ and one bone on the left side $(0.8 \%)$. Number of NF, number and percentage of bones are tabulated in Table 2.

$84 \%$ of the PNF was located on the posterior surface of the middle segment. $13.3 \%$ of the PNF was located on the posterior surface of the upper segment of the tibia (Table 3). All the PNF were directed downwards whereas SNF were directed upwards, and they were located in the lower segment.

\begin{tabular}{|ccc|}
\hline $\begin{array}{c}\text { Total Number of } \\
\text { Tibia }=\mathbf{1 2 0}\end{array}$ & $\begin{array}{c}\text { Total Length of Bone } \\
\text { TL, } \mathbf{( c m}) \\
\text { Mean with SD }\end{array}$ & $\begin{array}{c}\text { Distance of PNF from Upper } \\
\text { End of Bone, D } \mathbf{( c m}) \\
\text { Mean with SD }\end{array}$ \\
Right $=64$ & $35.57 \pm 2.48$ & $11.73 \pm 1.72$ \\
Left $=56$ & $35.50 \pm 2.55$ & $11.73 \pm 1.43$ \\
\hline Table 1. Measurements of Total Length of Tibia and Distance of \\
Primary Nutrient Foramina from Upper End of Tibia
\end{tabular}

\begin{tabular}{|c|c|c|c|c|c|c|}
\hline $\begin{array}{c}\text { Total Number of Tibia } \\
=120\end{array}$ & & Right & & & Left & \\
\hline No of foramina & 0 & 1 & 2 & 0 & 1 & 2 \\
\hline No of bones & 2 & 59 & 3 & 1 & 54 & 1 \\
\hline Percentage of bones. & 1.6 & 92.18 & 2.5 & 0.8 & 96.42 & 0.8 \\
\hline
\end{tabular}

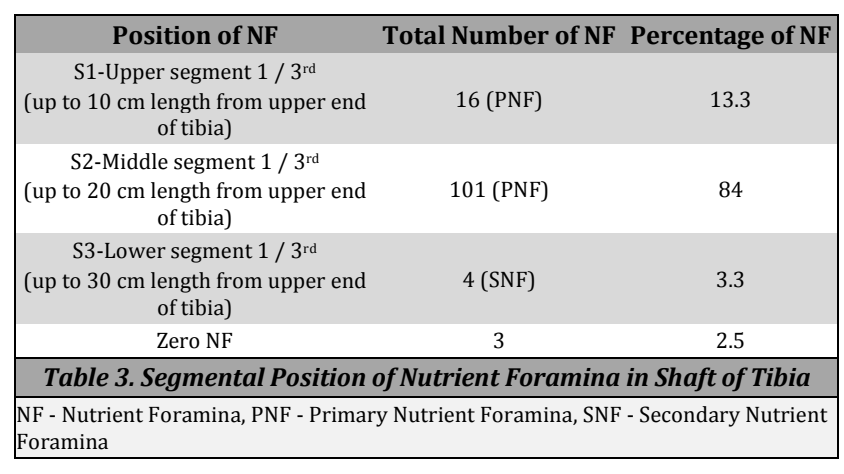

\section{DISCUSSION}

Blood supply to the long bones is mainly derived from nutrient artery which is essential for bone growth. If the nutrient artery is damaged while operating on tibia, it may result in ischemia which will lead to interference with the healing process. Therefore, anatomical knowledge of nutrient artery is crucial prior to surgery. ${ }^{1}$ In the present study a PNF was observed in $97.5 \%$ of tibia. Many authors also found single PNF in most of the bones. 2,10,11,12 In most of the tibia nutrient foramen was directed downward in the present study. This finding was in accordance with studies conducted by most of the authors, $10,11,13,14$ In the present study upward directed SNF was noted in 4 bones, PNF was observed on the posterior surface of shaft. SNF was located on the lateral surface of the lower segment. Most of the authors have also reported the location of PNF on the posterior surface in most of the bones. 2,10,11,15

Kamath $\mathrm{V}$ et al. observed PNF on medial surface in $2.82 \%$ ofbones. ${ }^{6}$ Regarding location of nutrient foramen on posterior surface of shaft, it was observed by most of the authors that it was located below the soleal line. ${ }^{16}$ This finding was similar to the present study. Average distance of nutrient foramen from proximal end was found to be $11.73 \pm 1.72$ on right and $11.7 \pm$ 1.43 on left which is similar to the study of Chavda H.S. and Jethva N.K. ${ }^{16}$ (Table 4). Comparison of sample size and mean tibial length in different studies is tabulated in Table.5

Mohan K et al. found PNF on upper $1 / 3^{\text {rd }}$ in $42 \%$ of bones, while in $52 \%$ it was on middle $1 / 3$.rd. No PNF was found in the lower $1 / 3^{\text {rd }}$ of tibia. ${ }^{10}$ It is similar to our study, in lower 1 / $3^{\text {rd }}$ SN Fonly observed. Vadhel C.R. et al. in their study on Gujarati population found occurrence of nutrient foramen on upper 1 / 3 in $99.5 \%$ of bones which was higher percentage than the present study findings. ${ }^{14}$

A single diaphyseal nutrient foramen, which was directed away from the growing ends (upper ends) was noted by Kamath $\mathrm{V}$ et al. ${ }^{6}$ in their study on tibia and fibula. Kamath $\mathrm{V}$ et al. concluded that the nutrient foramina of femur, tibia and fibula were located on the posterior (the flexor aspect) of the bones mainly. ${ }^{6}$ Knowledge of position of NF has a probable role in few cases of vascular necrosis. It is reported that the position of $\mathrm{NF}$ was directly related to the requirements of a continuous blood supply to specific aspects of each bone, for example, where there were major muscle attachments ${ }^{17}$ In leg the posterior compartment is the flexor compartment which has bulkier, stronger and more active muscles than the extensor compartment. Therefore, posterior compartment needs more blood supply than anterior compartment. In present study $96.6 \%$ of NF were present on posterior surface which is similar to previous studies $1,17,18$

\begin{tabular}{|cccc|}
\hline Sl. No. & Authors & Right (cm) & Left (cm) \\
1 & Ankolekar V H et. al, ${ }^{13}$ & 13 & 14 \\
2 & Joshi P, and Mathur S, ${ }^{19}$ & $14.53 \pm 3.77$ & $14.0 \pm 2.99$ \\
3 & Hiren S C and Nishita K J, ${ }^{16}$ & $11.8 \pm 1.93$ & $11.8 \pm 2.28$ \\
4 & Present study & $11.73 \pm 1.72$ & $11.73 \pm 1.43$ \\
\hline Table 4. Comparison of Mean Distance between Upper End of Tibia \\
and Position of PNF in Different Studies (D)
\end{tabular}

\begin{tabular}{|ccccc|}
\hline \multirow{2}{*}{ Sl. No. } & Authors & Sample Size & \multicolumn{2}{c|}{ Mean Tibial Length } \\
Right (cm) & Left (cm) \\
1 & Ankolekar V H et al. ${ }^{13}$ & 50 & 37.3 & 38.7 \\
2 & Joshi P, and Mathur & 50 & $32.84 \pm 8.4$ & $34.46 \pm 8.1$ \\
S, ${ }^{19}$ & & $35.1 \pm 2.3$ & $35.2 \pm 1.96$ \\
3 & Hiren S C andNishita K & 70 & $35.57 \pm 2.48$ & $35.5 \pm 1.72$ \\
4 & J, ${ }^{16}$ Present study & 120 & Table 5. Comparison of Sample Size and \\
\hline \multicolumn{5}{|c}{ Mean Tibial Length in Different Studies } \\
\hline \multicolumn{4}{|c}{} \\
\hline
\end{tabular}




\section{CONCLUSIONS}

The nutrient artery enters a bone through its primary diaphyseal nutrient foramen usually and is the major source of vascularisation to the bone. It is absolutely essential for the surgeon to have a sound knowledge of the location and number of these foramina, so as to prevent any inadvertent injuries during surgery. The present study of these parameters will provide useful data and aid those undertaking surgical interventions of tibia. It is very important for surgeons to have sound knowledge of precise topography of nutrient foramen which will help in preserving vasculature of the bone during various surgical procedures like fracture fixation, bone grafting, knee replacement surgeries and tumour resection. Understanding of exact location and distribution of nutrient foramen will help in avoiding damage to nutrient vessels during surgery. This will ensure less post-operative complications, as well as this helps in better outcome of operative procedure.

An orthopaedic surgeon operating on tibia must be careful in the middle $1 / 3^{\text {rd }}$, especially near the soleal line as majority of primary diaphyseal foramina were observed in this region. Our study provides details about the nutrient foramina that will benefit clinicians who treat injuries and diseases of the tibia. Surgeons should be mindful of soft tissue in the foraminal area during surgical procedures.

\section{Limitations}

This study was conducted in 120 bones only which was a small sample for the study. Authors could not incorporate more bones due to resource limitations in the department. Bones available in the department were of unknown age and sex; therefore, gender and age-based assessment were also not done in the present study. Further larger studies involving more bones of known age and sex from different geographical regions are necessary.

Data sharing statement provided by the authors is available with the full text of this article at jemds.com.

Financial or other competing interests: None.

Disclosure forms provided by the authors are available with the full text of this article at jemds.com.

\section{REFERENCES}

[1] Lewis OJ. The blood supply of developing long bones with reference to the metaphyses. J Bone Joint Surg $\mathrm{Br}$ 1966:38-B(4)928-33.

[2] Sharma M, Prashar R, Sharma T, et al. Morphological variations of nutrient foramina in lower limb long bones. Int J Med and Dent Sci 2015;4(2):802-8.
[3] Standring S. Gray's Anatomy. The anatomical basis of clinical practice. $40^{\text {th }}$ edn. UK: Churchill Livingstone/ Elsevier 2008.

[4] Trueta J. Blood supply and the rate of healing of tibial fractures. Clin Orthop Relat Res 1974;105:11-26.

[5] Taylor GI. Fibular transplantation. Microsurgical composite tissue transplantation. St. Louis: CV Mosby Co., 1979:418-23.

[6] Kamath V, Asif M, Bhat S, et al. Primary nutrient foramina of tibia and fibula and their surgical implications. Indian J Clin Anat Physiol 2016;3(1):41-4.

[7] Krishna SM, Kumar PU, Sirisha V, et al. Morphologic morphometric study of the nutrient foramen in dry human femur bones of telengana region. Int J Anat Res 2016;4(2):2464-8.

[8] Longia GS, Ajmani ML, Saxena SK, et al. Study of diaphyseal nutrient foramina in humanlong bones. Acta Anat (Basel) 1980;107(4):399-401.

[9] Rao VS, Kothapalli J. The diaphyseal nutrient foramina architecture--a study on the human upper and lower limb long bones. IOSR J Pharm Biol Sci 2014;9(1):36-41.

[10] Mohan K, Devaraj B, Ramanathan S, et al. Morphometric study of nutrient foramen in the long bones of lower limb. Int J Anat Res 2017:5(2):3943-48.

[11] Lee JH, Ehara S, Tamakawa Y, et al. Nutrient canal of the fibula. Skeletal Radiol 2000;29(1):22-6.

[12] Kizilkanat E, Boyan N, Ozsahin ET, et al. Location, number and clinical significance of nutrient foramina in human long bones. Ann Anat 2007;189(1):87-95.

[13] Ankolekar VH, Quadros LS, D'souza AS. Nutrient foramen in tibia-a study in coastal region of Karnataka. IOSR Journal of Dental and Medical Sciences 2013;10(3):75-9.

[14] Vadhel CR, Kulkarni MM, Gandotra AR. Anatomy of nutrient foramen of tibia-a study from Gujarat region. Indian J Clin Anat Physiol 2015;2(1):6-10.

[15] Pereira GAM, Copes PTC, Santos AMPV, et al. Nutrient foramina in the upper and lower limb long bones: morphometric study in bones of Southern Brazilian adults. Int J Morphol 2011;29(2):514-20.

[16] Chavda HS, Jethva NK. Morphometric study of nutrient foramen of adult human tibia bone. International Journal of Anatomy, Radiology and Surgery 2019;8(2):A005-A08.

[17] Kizilkanat E, Boyan N, Ozsahin ET, et al. Location, number and clinical significance of nutrient foramina in human long bones. Ann Anat 2007;189(1):87-95.

[18] Sendemir E, Cimen A. Nutrient foramina in the shafts of lower limb bones: situation and number. Surg Radiol Anat 1991;13(2):105-8.

[19] Joshi P, Mathur S. A comprehensive study of nutrient foramina in human lower limb long bones of Indian population in Rajasthan state. Galore International Journal of Health Sciences and Research 2018;3(3):34-42. 